\title{
Creative individuals, "Kaya Bola" exceptionalism and sustainable development in twenty-first century Ghana
}

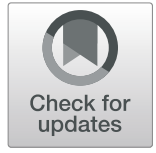

Ebenezer Owusu-Sekyere (D)

Correspondence: osekyere@uds.edu.gh

Department of Development Studies, University for Development Studies, P.O. Box 520, Wa, Ghana

\section{Springer Open}

\begin{abstract}
This article pays attention to the activities of Kaya Bola (KBs)_informal waste collectors in Kumasi, Ghana whose imperatives are given little attention in the sustainable development narratives. How their activities illuminate good livelihood practices, proper city governance, and foster economic empowerment are discussed using multiple research methodologies. As the article shows, KBs have used their exceptional skills in waste collection to launch themselves into sustainable urban employment. They are intensely situated in the specifics of articulations and imbrications in many other processes. The most useful are that beyond keeping the city clean, they have also emerged as a campaign to combat joblessness, social exclusion, urban discontent, and spatial fragmentation associated with rigid labor arrangements under the neoliberal economic restructuring. The article contends that their image as unruly and messy is misleading. Contrary, their contribution toward the urban space calls for a recalibration of policies toward achieving the SDGs.
\end{abstract}

Keywords: Ghana, Informal waste collectors, Kaya Bola, Sustainable development, Solid waste

\section{Introduction}

Many Sub-Sahara African countries today are defined by increasing urbanization amidst chronic financial constraints (Onyanta, 2016; UN, 2008). This situation has resulted in increasing urban unemployment; economic and social inequality and class segregation (Wilson, Rodic, Cowing, Whiteman, Stretz, \& Scheinberg, 2013). It was thus heartwarming when at the beginning of the new millennium, the United Nations (UN) entered into an anti-poverty framework that translated into eight stimulating Millennium Development Goals (MDGs) with target 2 of goal 1 aiming to halve by 2015, people without productive employment and decent work (Oteng-Ababio, Owusu-Sekyere, \& Amoah Samuel, 2017; UNDP, 2006). Realizing that the MDGs were expiring by 2015 without significant improvement in the worlds of work, UN-member states committed to develop a new set of goals to build on the successes of MDGs and extend these to the whole global population, including the poorest and most vulnerable (UN, 2014). It therefore came as no surprise when in September 2015, the 193 UNmember states consented to another development framework-the Sustainable Development Goals (SDGs) (Sustainable Development Solutions Network (SDSN), 2015;

(c) The Author(s). 2019 Open Access This article is distributed under the terms of the Creative Commons Attribution 4.0 International License (http://creativecommons.org/licenses/by/4.0/), which permits unrestricted use, distribution, and reproduction in any medium, provided you give appropriate credit to the original author(s) and the source, provide a link to the Creative Commons license, and indicate if changes were made. 
UN, 2014). Achieving SDGs will require innovation, collaboration, and involvement of all stakeholders from both the formal and informal sectors.

In Ghana, one group that has the potential to drive the SDG agenda is informal solid waste collectors popularly called Kaya Bola (KBs). They are creative individuals whose activities involve turning new and imaginative ideas into reality. They are described as creative because their activities are somewhat innovative and risk-taking and also have the ability to plan and manage waste collection for economic gains (Sustainable Development Solutions Network (SDSN), 2015; Grant \& Oteng-Ababio, 2016). Their potential stems from the fact that over the years, the prevailing mode of solid waste management (SWM) has been the adoption of "Western" styled grid-based systems. The systems are premised on a five-staged hierarchy involving waste reduction, reuse, recycle, incineration, and disposal at landfills (Forbes et al., 2001) with little success story to tell. As formal SWM companies fail to keep pace with growing demand for waste management services that are effective and efficient, a "niche market" has been created for the KBs. Their principal importance in the agenda is that they are deeply intertwined with enterprises of public health and of urban planning and with discourse on urban governance and right to urban life (Manton, 2013). This tendency has thus created complex networks of creative individuals whose overall contribution to job creation remains largely understudied and not clearly understood. These individuals who employ exceptional skills do so as a way contributing their full potentials for overall economic growth of their cities. However, there is still little systematic knowledge on embedded organizational vitality and dynamic networks on them. How their activities illuminate good livelihood practices, proper city governance, and foster economic empowerment have also received little academic and policy attention. The few researches available describe them as unruly, messy, and to some extent harmful to the urban environment (Oteng-Ababio, 2011; Sustainable Development Solutions Network (SDSN), 2015; UN, 2014).

Even though some KBs can be a nuisance to the urban space as they are accused of dumping solid waste at unapproved places among others, this article excludes that scope and rather unmask their creative skills. It highlights their value and argues that for Ghana to actualize SDG 6 which aims at ensuring universal access to sanitation facilities by 2030 and SDG 8, which aims at providing productive employment and decent work for all, the contribution of KBs cannot be overlooked. This is against the background that the vision of the SDGs is based on a policy structure that is envisioned to provide equal opportunities for all stakeholders (whether formal or informal) in terms participation and financial arrangement (Grant \& Oteng-Ababio, 2016; OtengAbabio et al., 2017). The article contributes to our understanding on informal labor outcomes by unveiling their creative skills, often excluded from the sustainable development narratives. In particular, it elaborates on ceremonies of relationship that signify for us a sacred character to knowledge generation as well as relationship building with the informal sector. It adds to the ways in which informal sector can be integrated into the existing development protocols such that the ideals of the SDG which hinges on inclusivity can be achieved. The article is arranged as follows; the introductory paragraphs are followed by the explanation of key concepts foregrounding the study. The methodology is presented in the third section while section four discusses the results detailing the potential contribution of KBs to urban employment and environmental 
sustainability in Ghana. Finally, the last section argues for the need to develop an integrated approach that formalizes the KBs activities with formal waste managers to ensure environmental sustainability.

\section{Conceptualizing Kaya Bola, exceptionalism and sustainable development}

Kaya Bola or KBs is a localized term in Ghana which refers to informal waste collectors who operationally use simple tools like plastic containers, wooden boxes, and wheelbarrows among others for solid waste collection. They make do; being creative and tapping into new technologies, however crude it may be to be part of the base economy (Grant \& Oteng-Ababio, 2016). Their involvement in the solid waste management sector has signaled the institution of a new form of waste management services alongside the old: substantively rational delivery. Exceptionalism as used in the context of this paper refers to the extraordinary skills deployed by the KBs in their worlds of work. Contextually, sustainable development reflects the opportunity to advocate for positive change built on the values of solidarity, human dignity, care for creation, and inclusive participation (Sustainable Development Solutions Network (SDSN), 2015).

In Ghana, the best efforts at sustainable development still remain nascent (Sustainable Development Solutions Network (SDSN), 2015; UN, 2014). In the area of solid waste for instance, the extent of the resources required for its management means that attention has to move beyond the realm of engineered solutions to become a matter for political consideration within municipal governments; nation states and international organizations (Davis, 2006). It is argued further that emphasis has to be placed on non-state actors who are active service providers as well as participate in the discourse on the best strategies in which waste could and should be governed (UN, 2008). One key non-state actor deeply involved in solid waste management is the KBs. They form part of the broad informal economic activity that was first discovered by Keith Hart-a British anthropologist in 1971 (Hart, 1973). The term informal sector was used to describe unaccounted employment opportunities in the world of work (Hart, 1973; Oteng-Ababio, 2018). Hart used the term to describe how unskilled migrants from rural communities who could not find wage employment in urban Ghana negotiated a living by engaging in low-income and unregulated jobs (Chen, 2012). Particularly, Hart was thrilled by the potential productive value of "this world of economic activities outside the organized labor force" and questioned the desirability of conventional economic policies focused entirely on the formal sector (Hart, 1973, p. 68). Monumentally, these unregulated activities provided the poorest, marginalized, and neediest with much-needed opportunities to earn a livelihood.

Studies on the burgeoning urban employment stereotypically portrays informal workers including the KBs as generally comprising uneducated, unskilled labor who remain glued to live and work manually for survival (Oteng-Ababio, 2018). The literature posits that informal workers are understood as unable to break through the barriers of social and legal downgrading that trap them in cliental forms of political incorporation and contribute very little or nothing at all to the urban economy (see Meagher, 2003). Such description is due to the conventional approach, often Western-oriented understanding of what constitute sustainable solid waste management. However, the reality is that describing sustainable solid waste management based solely on such conventional approaches is a deviation from local realities. But largely ignoring and undervaluing the 
contribution of the so-called indecent employment by city planners only privileges the rational-modernist model of enterprise which is based on capital-intensive technologies (Gough \& Langevang, 2016).

Unfortunately, the significance of the KBs to sustainable solid waste management has been glossed over for a long time, leading to a situation where they are either located outside the boundaries of "decent" entrepreneurship, ignored, portrayed as temporary or transient, or simply asserted to have little or anything to do with what is viewed as mainstream sustainable solid waste management (Williams \& Nadin, 2010). Like other informal workers, they are often described as "murky," "shadow," "hidden," or "underground" (Gërxhani, 2004; Schneider, 2005). They are generally seen as lacking in regulation, structure, and institutionalization and operate as a non-registered, illegal industry (Guha-Khasnobis, Kanbur, \& Ostrom, 2006). It has been argued that the emergence of KBs is due to the availability of many able-bodied unemployed urban youth willing to collect solid waste purely for survival (Obirih-Opareh, 2003; Oteng-Ababio, 2010). It is further contended that their involvement in solid waste management is due to how the private sector in charge of solid waste management is structured to suit the city's neighborhood structure (Obirih-Opareh, 2003; Oteng-Ababio, 2010). From that perspective, the formal private sector operated in high-income, low-density areas while the low-income, high-density communities were rarely served. This socio-economic stratification of the society may partly have accounted for the genesis of KBs in the solid waste management industry. This dichotomy however appears to be fading in recent times because the latter is becoming more professional in their pursuit and therefore more acceptable in all neighborhoods (Oteng-Ababio, 2018).

Irrespective of when and where they entered the solid waste management industry, Medina (2008), observed that KBs belong to vulnerable groups such as recent migrants, the unemployed, children, and the elderly. He further suggests that KBs survive in a hostile social environment, sometimes rejected by society, and work in selected neighborhoods, on the streets, at the beaches, and in open dumps, where daily contact with all kinds of waste, including hazardous and medical waste, poses risks to their health (Cointreau, 2006). In their day-to-day operations, they often scatter the contents of waste bins to salvage anything of value for recycling which is processed, sorted, baled, crushed, or granulated before being sold mainly to middlemen, who often earn large profits while the waste pickers themselves are paid far too little to escape poverty (Medina, 2008). KBs have thus gained unmatched prominence as a conventional wisdom in international development planning in terms of solid waste management and also as a livelihood choice (Chen, 2012; Thieme, 2017). One can safely conclude that they are directly linked to the main objectives of development: increased production, job creation, and combating poverty. KBs have emerged to contribute meaningfully to the social, economic, and political life of the urban systems.

\section{Methodology}

\section{Study context}

The study was conducted in Ghana's second largest urban center, Kumasi (Fig. 1), regarded as one of the fastest growing cities in West Africa (GSS (Ghana Statistical Service), 2008). The rapid economic activity in the city has resulted in increased output 


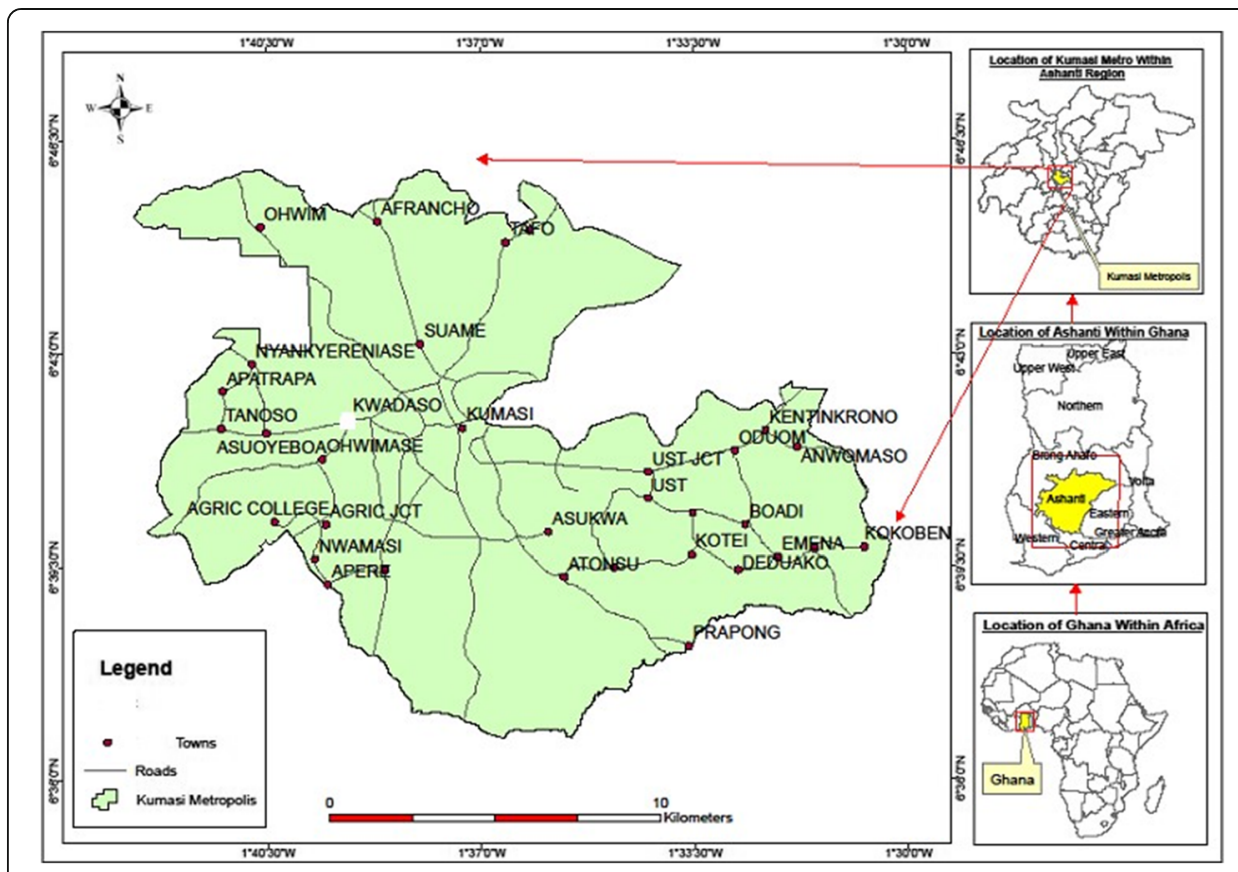

Fig. 1 Map of Ghana showing the study area

levels, changes in consumption patterns, improved life style, and an increase in ruralurban migration. Undoubtedly, the Metropolis, like other metropolis in most developing nations, is experiencing increasing and unprecedented population growth rates. A city which had a population of 346,336 in 1970 and 487,504 in 1984 recorded over 2,022,919 people in 2010, representing an annual growth rate of 5.4\% (GSS (Ghana Statistical Service), 2008). The growth has also impacted the rate of solid waste generation in the city. For instance in 1995, the rate of domestic waste generation in Kumasi was estimated at 600 tons per day. By 2005, 1000 tons of solid waste was being generated, reaching 1500 metric tons in 2010 (GSS (Ghana Statistical Service), 2008). Current statistics from metropolitan authority indicate that the city now generates over 2000 metric tons daily.

\section{Data collection and analysis}

This qualitative research combined in-depth interviews and firsthand observations of how the KBs collect and deposit solid waste. The in-depth interviews involved the use of a semi-structured interview guide similar to the scholarly work of Oteng-Ababio (2010). The semi-structured interviews were composed of the same primary set of questions, with reminders nested below each one. Averagely, each interview lasted for $1 \mathrm{~h}$. In cases where interviewee's responses were seen to have reached saturation point and were no longer yielding novel insights, the interviews were curtailed. The first set of data for the research was obtained from $40 \mathrm{KBs}$ who were purposively selected from a pool of $75 \mathrm{KBs}$ who had earlier agreed to participate in the study during the preliminary visits. The purposive sampling was adopted because the interests lied in the experiences of interviewees who had been in business for over a year. 
They were selected from the Dompoase landfill site where they normally deposit the collected waste. The face-to-face interview technique was adopted using semistructured interview guide. The research tools were developed by the research team in conjunction with the key informants who were identified in the reconnaissance survey preceding the actual data collection, an approach consistent with interview methodology (see Dunn, 2010). This enabled an assessment of the key issues to probe. The interview guide was structured into sections to cover the scale, socioeconomic fortunes, service beneficiaries, as well as challenges and coping strategies. These interviews were carried out in the morning when the KBs were busy at work. Although there were some difficulties with the interviews because they suspected intrusion, persistent assurance and re-assurances attracted their eventual cooperation. The on-site interviews also provided the opportunity for participant observation and to experience at first hand some of the challenges and also their coping strategies.

The later complementary interviews with service beneficiaries were mostly carried out on weekends when most of the respondents were at home. The issues that were covered included frequency of waste collection, the person/institution responsible for waste collection, the actual person/persons who collect the waste, the charges for service, and general satisfaction/impression with the state of solid waste collection in neighborhood among others. The observational methods that were adopted also allowed for gained insights into their modus operandi, power relations with the formal sector, and other key players in the industry. Practically, a careful attempt was made to keep the field records focused and systematic in order to generate comparable data sets to aid the analysis. The last stage of data collection involved detailed interviews with six officials from the Waste Management Department, three private waste management companies, and some waste management experts. The in-depth interviews with the public officials probed their perceptions about the operations of the KBs and the current legal regime governing such operations. The interviews also identified the relationship and linkages and the drivers of their business including both the demand side and the supply side and their importance in the entire waste management system in the city. Finally, the interviews particularly sought insights into the future of such operations in so far as the authorities were concerned. All the interviews were transcribed verbatim. Themes reflecting the richness of the participants' experiences were created. These themes were then connected to each other based on similarities and apparent interrelationships. For the purposes of clarity, the themes were checked with the transcripts to ensure that the connections worked for the primary source material. Once a coherent list of related themes was finalized, extracts representing themes were selected and were presented as direct narratives.

\section{Results and discussion}

\section{Conceptual roots of Kaya Bola}

The field evidence indicated that popularity of KBs was in response to two sets of factors: inefficiencies in formal solid waste collection and as a campaign to combat poverty. The data collected revealed that Ghana's SWM policies in the past periods 
have often been based on policies prescribed and dictated by the World Bank without paying enough attention either to indigenous socio-cultural and value systems or to analyzing and interpreting its relevance in the waste management evolutionary continuum. The results from the data collection also showed that the imported policies were premised on large-scale centralized technical systems and the polluter-payprinciple which is aimed at introducing accountability into solid waste service delivery, a view in sync with studies by Baud (2001), Oteng-Ababio (2010), and Moore (2011). The interviews with some key informants indicated that the rationale for the polluterpay-principle was a way to help government reduce the colossal amount of money that is expended on the management of solid waste. Though the salutary effects could not be taken for granted, the empirical proof that polluter-pay-principle had actually worked was rather weak.

It was observed that the system was fraught with weak operational capacities, limited financial resources due to unreliable revenue sources, limited community participation, and poorly designed collection system. The effects are choked drains, "mountain" of waste at public places and the escalation of flooding events and continuous cholera outbreaks. Since service quality from the formal sector was not up to the required standard, the KBs who understand the economic, historical, and socio-cultural arrangements of the city emerged to fill the service vacuum. As observed in an interview with the public relations officer of the Kumasi Waste Management Department (KWMD):

The irregular collection of the formal service providers often resulted in unsightly 'mountains' of solid waste in most neighbourhood. This situation has compelled the public to seek an alternative waste disposal system, hence the reliance on informal waste collectors, he concluded.

Beyond the inefficiencies in the existing solid waste management systems, the interviews further revealed that the emergence of KBs was as result of widespread unemployment and increased poverty associated with the broad economic shift toward temporary, contingent, and flexible labor arrangements under the neoliberal structural adjusted program (SAP) prescribed by the World Bank. During interview sections with some KBS, they unanimously agreed:

We started getting involved in solid waste collection as a survival strategy to meet the challenges of unemployment. The many years of low economic activity because of the changes in government policies where jobs in the government sector was not easy to get pushed many of us into the informal waste collection.

There are significant scholarly works that supports the concerns raised in the interviews on the relationship between the SAP and the growth of KBs (Oteng-Ababio, 2018; Owusu, 2013; Yeboah, 1998). Supporting the reasons offered by the KBs, a key informant at KWMD opined that the popularity of KBs is also due to the urban bias and labor-related policies that governments in Ghana have pursued over the years where planning is deliberately urban centered to the detriment of rural areas. He continued: 
This deliberate policy means that leaders devoted the vast majority of resources toward urban development to the detriment of rural areas with direct support from development agencies and international financial institutions. The effects of such decisions were the migration of the youth to the urban centers that were not sufficiently prepared to provide formal jobs for the new urban dwellers. For such people, the only source of hope was to go round picking waste, he concluded.

This resonates with the findings of Oteng-Ababio (2011) in a similar study on informality in Accra, Ghana's capital city. In terms of demographic characteristics, all KBs covered in the study were males between 18 and 45 years. Approximately $70 \%$ of KBs had not had any form of formal education; $25 \%$ had completed basic education while the remaining $5 \%$ indicated they dropped out of school at secondary level. The demographic characteristics of the KBs suggest that manual waste collection is typically a male-dominated activity. The interviews and field observations showed that the job was tedious and energy sapping and therefore women and the aged could not endure. In discussions on years of work, $24 \%$ of KBs had been in business for less than 5 years, $56 \%$ had collected solid waste for about 10 years, while $20 \%$ had done the job for more than 10 years (Fig. 2).

The interactions, interviews, and participant observations revealed that timing was quite pervasive and spatially defined. Mostly KBs started waste collection at about 0400GMT reaching a crescendo at about 0600GMT where the solid waste generated during the previous day might have been added. This period also coincides with the morning rush hours (between 5 am and 9 am) and therefore KBs reported spending more time, usually about $3 \mathrm{~h}$ in traffic before reaching the final disposal sites but this did not deter them from plying their trade.

\section{Operational imperatives of Kaya Bola}

A careful analysis of the responses from the KBs showed that about $55 \%$ of their service beneficiaries were from Aboabo, a low-income community mainly made of migrants; 25\% were from Bantema, a middle-income community; while 20\% serviced client from Ahodwo, a high-income community. Evidently, KBs were involved in house-to-house collection and some other public institutions. They followed simple pathways in their operational processes. In their day-to-day operations, apart from disposing off the waste

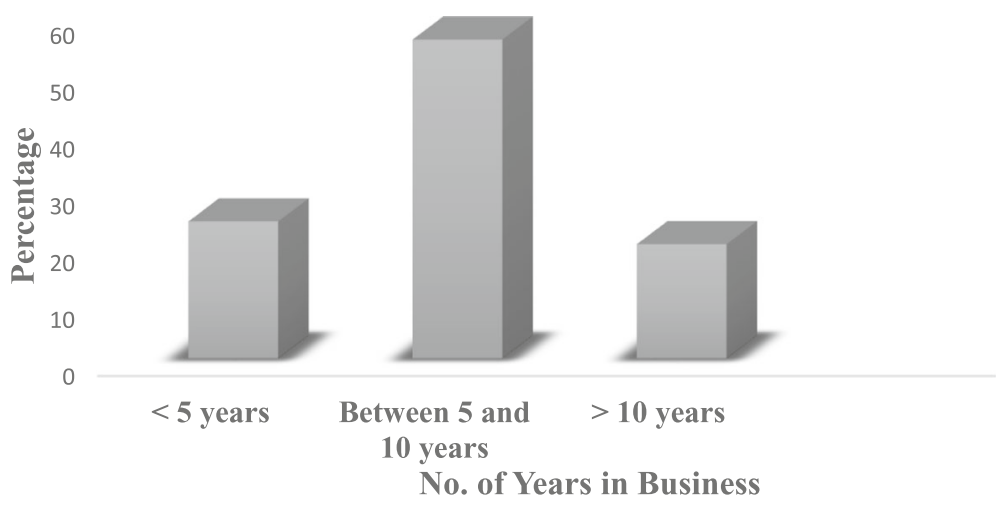

Fig. 2 Number of years in waste collection 
at designated disposal sites, they also collected large volumes of materials for recycling which were sold mainly to middlemen. Again, KBs played dualistic roles: not only did they cater for clients within low-income communities, they also catered for clients in medium- and high-income communities, see Fig. 3.

Solid waste collection by KBs followed similar geographic pattern as the formal sector. While they served clients from all residential categories, their services were more visible and relevant in the low-income communities. Over 80\% (Fig. 3) of respondents in poor neighborhoods patronized their services. Through the in-depth interviews, issues such as affordability, reliability of service, and personal affiliations were among the reasons offered for their popularity. In other words, the cost element inherent in the usage of KBs significantly increased the probability of households choosing their service. This observation has great significance for any future policy consideration regarding the institutionalization of KBs in SWM since the adoption and acceptance of any policy is highly dependent among other things on its financial implications. Again, the nature of access routes in the unplanned and semi-planned communities benefited KBs because they were able to navigate through the narrow and erosion-ridden roads to the door-step of their clients. Additionally, the popularity of KBs stemmed from their reliability and promptness. A client at Ahodwo, a high-income residential community, expressed:

As for this people (KBs) anytime you call them, they will come but for the private company that is responsible for this community, sometimes for over one month, they will not come and pick the waste, so I have stopped calling them now. All they know is to come and collect huge sums of money without working, for now I have chosen to work with the Kaya Bola because it is cheap and reliable, he concluded with some optimism.

The narration provides evidence and re-enforces the popularity of KBs in the Municipality. These findings concurs with studies of Oteng-Ababio, Arguello, and Gabbay (2013), who observed that activities of KBs in Accra is not confined only to the low-income neighborhoods but equally prominent and conspicuous in highand middle-income areas. Their results indicated that $60 \%$ and $80 \%$ of respondents

$$
\begin{aligned}
& \text { 든 } 90
\end{aligned}
$$

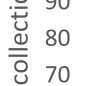

$$
\begin{aligned}
& \text { 范 } 60 \\
& \text { 苋 } 60 \\
& \begin{array}{ll}
3 & 50 \\
\hline & 40
\end{array} \\
& \text { 空 } 30
\end{aligned}
$$

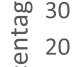

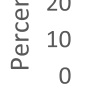

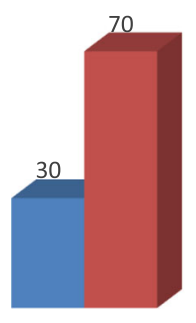

High

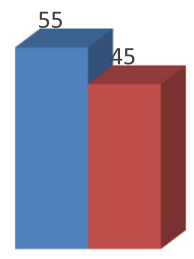

Medium

Household classification

- KBs $\quad$ Formal sector

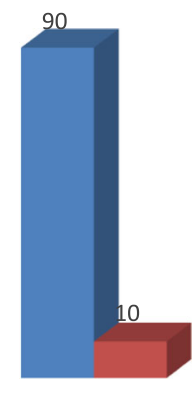

Low

Fig. 3 Kaya Bola services in terms of residential classification 
in the middle-income communities of Accra Metropolitan Area and Ga District respectively, used the services of $\mathrm{KBs}$ while $60 \%$ in the low-income areas of Tema Metropolitan Area also used their services. Another insightful observation was the fact that KBs served their client more frequently than the formal waste collectors. Figure 4 shows that over $80 \%$ of clients who patronize the services of KBs had their waste picked up every day compared to the formal waste collectors who frequently serviced their client once in a week.

This infrequent service provision from the formal waste collectors often brought confusion and misunderstanding between clients and the formal service providers. A respondent shared his frustration in an interview;

My brother as we agreed upon, they (formal sector) are to collect our waste twice in the week but for almost three months they pick the waste just once in a week. This situation creates unsightly scenes as dogs, birds and other domestic animals feed on the garbage. What makes it even more annoying is the plenty mosquitoes and houseflies that the garbage attract. Meanwhile we pay them every month, how can this happen? He asked in anger.

Again, it was observed that KBs operated in their immediate geographical and social space and that enhanced the frequency with which they serviced their client. This gave them competitive advantage and so were able to retain their customers than the formal service providers. This means that service beneficiaries had higher level of trust in the KBs; a trust which was not only built through professional relationship but based on the social capital theory as well (Tukahirwa, Mol, \& Oosterveer, 2011). The kind of social arrangements between the client and the KBs enhanced not only service delivery, but to some extent, translated into service quality.

\section{Collection technology of Kaya Bola}

The collection tools of KBs were rudimentary including pickaxe, shovel, chisel, and baskets among others. The more experienced and well-endowed KBs used wheel-barrows, bicycles, and engine powered tri-motors, popularly known in Ghana as the "Motor King" to carry the collected solid waste to the final disposal sites, see Fig. 5.

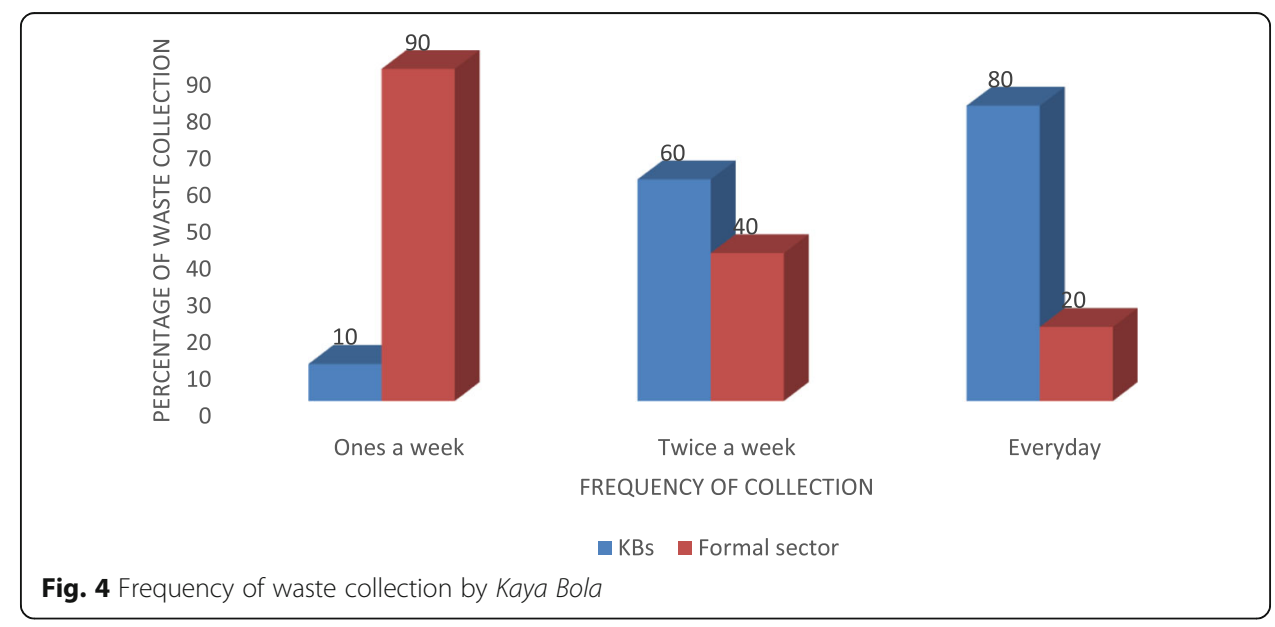




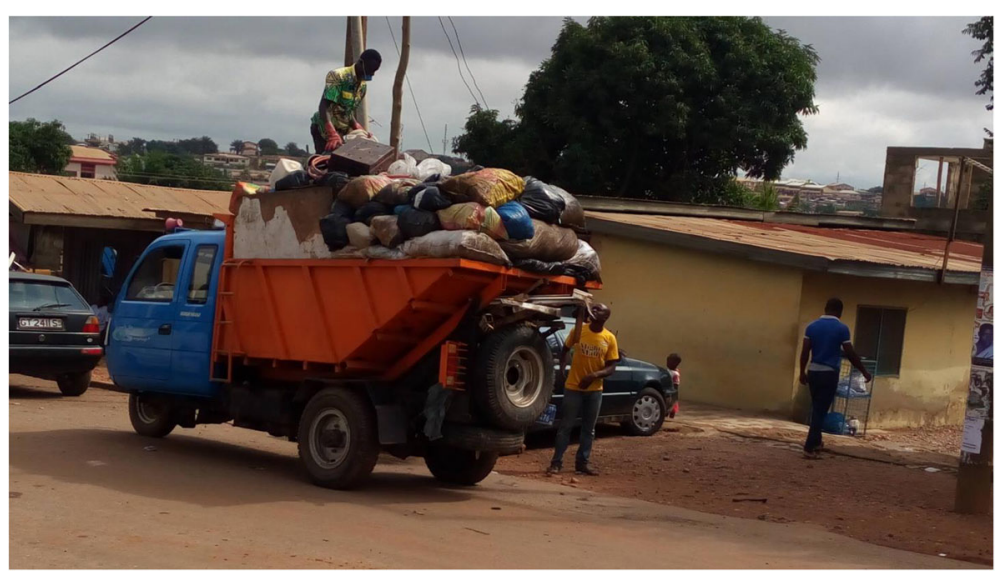

Fig. 5 Informal waste collectors with "Motor King" loading solid waste

The acquisition of waste collection equipment further exemplified the zeal and determination of KBs to succeed. Kofi ${ }^{1}$ explained how he acquired his Motor King:

I first started with a basket, so I always saved part of my daily sales till my savings could purchase this Motor King am using. Though it is expensive $\left(\mathrm{GHC} 9600^{2}\right)$, I make more money with this than when I was using the basket because I am able to collect more waste and also able to work for more hours.

Unlike Kofi, Addae rather opined:I got my Motor King on 'work and pay' system through the government's youth support programme. The arrangement is that you deposit a third of your daily sales with the bank that facilitates the process. This, you will do till the entire cost is paid.

He however explained that it takes a long time (usually up to 5 years) before the last payment is made. This therefore keeps one in debt for a long period and also affects the lifespan of the machine. For Steven, he hires the wheel barrow on daily basis from the agents at fee of GH $20.00^{3}$;

... I have to do that because for now I do not have enough money to buy some on my own as the little money I have will have to be used in paying my children's' school fees. He concluded in subtle voice.

For the respondents who used baskets and the boxes, the cost of acquisition was not much of a problem since the prices were comparatively affordable. From all indications, KBs who used baskets and the boxes nurtured the hope of acquiring an engine-powered tricycle someday. This finding confirms the thinking of the dualist school who believes that the informal sector of the economy basically relies on low-level and rudimentary technology to carry out their productive activities. They further contend

\footnotetext{
${ }^{1}$ All names do not represent the actual names of respondents

${ }^{2}$ About USD 3000 at January, 2015 exchange rate

${ }^{3}$ About USD 6.00 at January, 2015 exchange rate
} 
that they are involved in small-scale production and that their major pre-occupation is to make a living for themselves and other close family members (ILO, 2002).

Unlike the prevailing formal systems, KBs did not provide solid waste bins to clients. As part of the complimentary efforts to the formal sector, they empty bins that have been left uncollected for days and do not pass the cost to the formal company in charge of that jurisdiction. Such was the kind of relationship that existed between them and the formal sector in urban Ghana. This observation reechoes the findings of Oteng-Ababio et al. (2013), who observed that the Kaya Bola worked alongside the official sectors, albeit in an officially non-recognized capacity.

\section{Challenges and coping strategies}

Notwithstanding their immense contribution of $\mathrm{KBs}$, there were challenges that threatened their existence. The interviews revealed that KBs lacked political support, operated in an unfriendly environment, and often did not benefit from protective clothing. As one of the KBs indicated in the interview section:

As the political parties come to campaign and talk about their plans for managing solid waste, none of them talk about our business. It is therefore not surprising that any time government talks about supporting private waste management companies, we are not mentioned.

Though awareness is gradually being created on the significant contributions of KBs, in the discourse concerning appropriate SWM practices, very little attention is given to their skills, endurance, and resourcefulness. KBs were also seriously threatened by disease organisms, sharp objects, and other hazards in the waste as they generally lacked protective equipment. This was because hospital waste from private hospitals, liquid waste from baby diapers, as well as other hazardous substances were all picked together, thus increasing the risk of infections. The KBs confirmed in the interviews the perceived health effects of the business, albeit at different degrees and in varying dimensions. The commonly perceived health problems included eye irritation, respiratory diseases, and skin diseases among others.

Additionally, KBs operated in hostile environment and lacked respect. They were regarded by city authorities as nuisance, embarrassment, and criminals. For these reasons, some KBs nurtured the hope of quitting the job a day to come. Some KBs (about $45 \%$ ) believed that there will be an opportunity to quit waste collection one day. They shared their views in the follow-up interviews:

There is no respect in this job. I am doing it now because there is no job to do. When I get a better job, I will quit, (an Informal solid waste collector at Ahodwo).

Another one at Aboabo opined:

One cannot do this job for a long time because it is tedious as one has to move from house to house to collect the waste. The waste is sometimes too heavy to push to the dumpsite. If I don't quit this job, I may grow older than my actual age. I want to go and learn a trade after I have made some savings. 
Despite the challenges, formation of local associations, social networks, and operating outside the concessions of the formal sector emerged as the main coping strategies. But more importantly, the income incentive alone was motivating enough to build their resilience and keep them in business. For instance, some KBs indicated that income from waste collection was almost two or three times higher as compared to formal sector jobs. It was observed that KBs earned averagely, a monthly income of about GHC 650.00. This figure was based on guess estimates from the respondents because many of them were not literate enough to keep proper records on the amount of money they earn in a day. The findings confirm the viability of the industry in a country where the official minimum wage for 2015 was GH\$ 7.00 (US \$ 2.12) and that translated to GHC 210.00 per month. Thus, this economic incentive appeared to have stimulated the thinking that it was better to remain and earn more income than to chase non-existing formal employment that did not also pay "better" salaries.

\section{Achieving SDG 6 and 8: formalizing Kaya Bola}

The results so far points to the fact that the adoption of formal SWM systems seems a dead-end-road venture. The formal systems in Ghana have not yielded the desired results in achieving MDG 7 and MDG 1-keeping the city clean and creating jobs. There is no hope the same old approach can deliver new results-SDG 6 and 8 (environmental sustainability and decent urban jobs). The old paradigm were not successful not because they were technically deficient but because of their misfit in terms of the social, geographical, and economic contexts in which they were implemented.

The inherent problems therefore call for a more integrated approach which is in sync with the philosophical grounding of the SDGs that recognizes the contribution of informality in all aspects of development. Such integration will not only empower the KBs, but will also take into account specific local conditions of the country. As observed by Grosso (2016, p. 1), the complexity of the SDGs means "it has to be tackled from many different points of view, with all actors playing their roles towards attaining a common objective. No magic wand exist, nor universal solutions applicable to every geographical and social context." This means that for countries to achieve SDGs 6 and 8, an integrated approach is the way to go.

The question then is how should such integration take place within the Ghanaian context? The way forward lies in determining proper political, legal, cultural, and social conditions that can be adopted as the best possible approach to the integration. This will however require the collaborative efforts of state and local authorities, the international development community, and KBs themselves. The overall goal should be to build a better functioning, more inclusive, solid waste management system. For these reasons, an integration model is proposed in this study (Fig. 6). Specifically, the study proposes four major areas where the KBs can be integrated with the formal solid waste management sector.

The benefits and responsibilities of each actor in the integration process is a two-way affair. The first step of the integration advocates for the need to establish an enabling institutional and supportive regulatory framework that will recognize and support Kaya Bola activities. The arrow in the diagram has a two-way direction which means that the Kaya Bola will have to submit themselves to all institutional regulations such as fees to 


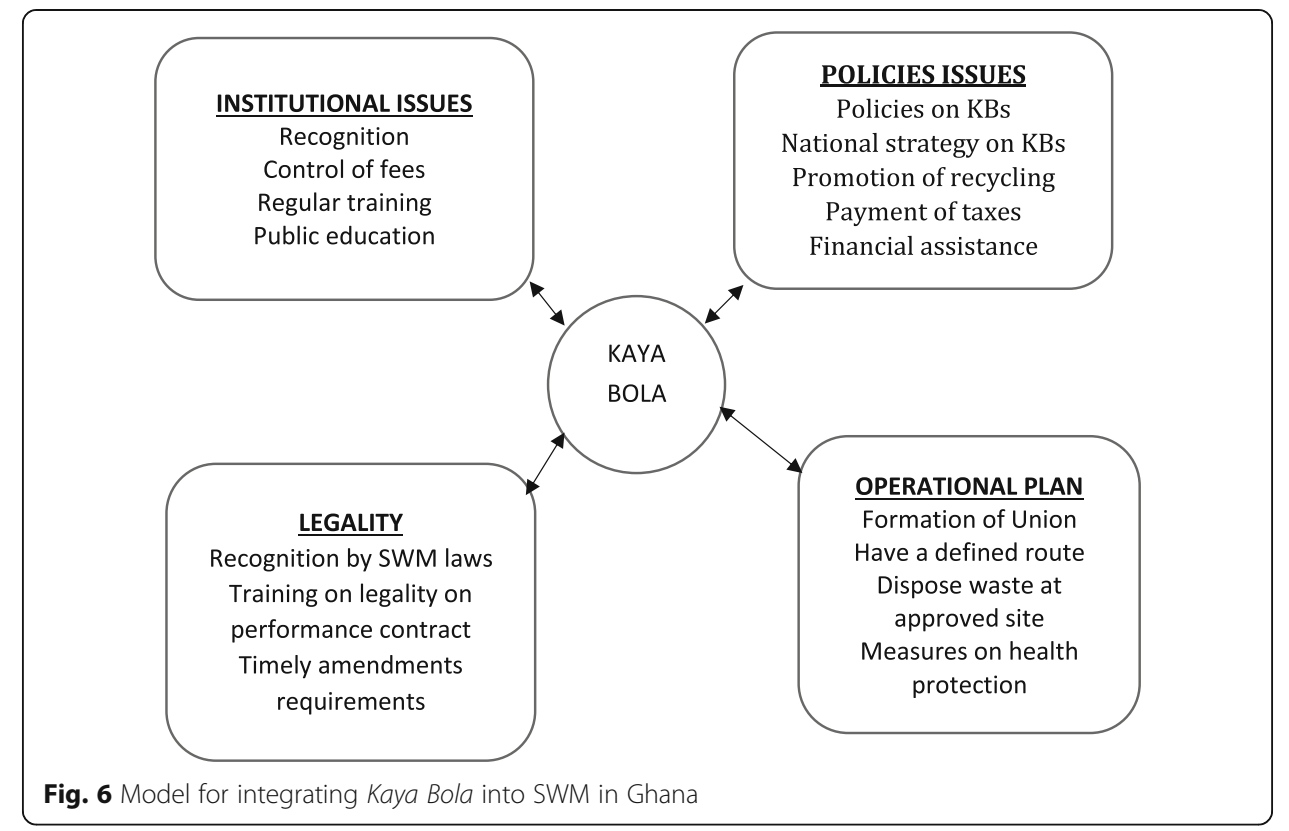

charge and disposing of solid waste in an environmentally friendly manner that is in accordance with established procedures. In this way, nationally established institutions on solid waste management will in turn recognize and protect them and will also help with mass public education on their activities. This institutional recognition could help them improve upon their funding sources and technology, which is still rudimentary and limits economies of scale.

The second level of integration has to be done at the policy level where policies on solid waste management and its related amendments will have to take into consideration, the role of Kaya Bola. In this sense, they should be taken into consideration in the development of national strategic plans on sanitation and its related issues. This also means that they will have to benefit from all training on proper approaches to SWM especially issues on recycling and reuse. This is very important considering the fact that informal waste collectors are always at the first line of waste collection and therefore is in a position to collect first-grade valuable waste that can be recycled and reused. Considering the fact that they are collecting waste at a fee, they should be made to pay taxes through the local authority under which they operate. The payment of the taxes will enable them to form local unions to bargain for their share of the national cake as is the case in some Southern American countries (Medina, 2008). This will also require that government, both at the local and national level, need to find ways that allow them to report data in terms of numbers, income, number of clients, and many other variables without fear of reprisals.

The third level of integration has to be done at the legal level. In this direction, the enactment of all laws concerning proper SWM should also take into consideration the continuous presence of Kaya Bola activities in urban Ghana. Legislations, legal regimes, sanctions, and exemptions should apply to them as well. They need to be aware and educated on issues such as performance contract, laws regulating the management of solid waste and above all, should be knowledgeable on the implications of flouting the laws and the sanction that will be applied. 
The last level of integration and perhaps the most important is the operational level where the Kaya Bola interacts with their client and the general public. Conscious efforts should be made at this level to help them in identifying proper spaces designated for waste disposal. Recognizing the role of the informal sector at the operational level may be desirable but daunting: desirable because the informal sector continues to play an important role within the value chain due to its employment-generating potentials, experience, and work ethics; daunting due to its modus operandi and fragmented nature. The challenge is to find a way to mobilize and involve various individual groups with diverse networking agendas and interests in a cooperative body and to dovetail their experiences professionally into the formal system.

\section{Conclusion}

Significantly, this study has contributed to the understanding of how the informal sector, specifically KBs, has used their creative skills to fully participate in the urban economy through informal waste collection. While they work to keep the city clean, the same occupation has presented opportunities for innovations to generate wealth and enhance quality of life. The KBs also work to complement the formal sector, a situation which portrays a symbiotic relationship and eventually impacts positively on SWM in the short, medium, and long term. The services of KBs are cost-effective, save energy, and protect scarce natural resources. At the same time, local authorities save significant funds, which they would have otherwise paid to formal waste collection contractors. The analysis pursued in this study clearly indicates that both the informal waste collectors and the formal sector are multifaceted, operate at different levels but at a point, there is convergence in operations. Notwithstanding the obvious economic and political power disparity between informal waste collectors and the formal sector, the relationship between them has been a two-way street-indeed, that has always been the case.

Analysis of the role of the informal sector in SWM is not a novelty as indicated in the literature. What is however missing from the available discourse and what this study has added is the levels where integration between the informal and formal sector can be effective in achieving SDGs 6 and 8. While I agree that the proposal may not be exhaustive, the belief is that it may offer a pathway for building a more exhaustive model of inclusion. This study has shown that any attempt at pursuing solely "Western-oriented" SWM policy that either seeks to erode or fails to recognize local ingenuity and initiatives will be problematic toward the achievement SDG 6 and 8. In other words, policies and programs that fail to galvanize and integrate indigenous knowledge of the people by recognizing their social, cultural, and economic conditions might not achieve the desired results. Finally, the paper further argues that the elements of inclusivity are already evident in the various social networks that guide the interactions between the formal and informal sectors in Ghana. However, these bonds still need formal recognition and deliberate policy interventions aimed at enhancing their potential to foster sustainable waste management.

\section{Abbreviations}

ABC: Ayitey Brothers Company; CLTS: Community-led total sanitation; GTZ: German Technical Cooperation; KBs: Kaya Bola; KMA: Kumasi Metropolitan Assembly; KWMD: Kumasi Waste Management Department; KWML: Kumasi Waste Management Limited; MDGs: Millennium Development Goals; MERC: Micro-Enterprise Refuse Collection; SDGs: Sustainable Development Goals; SWM: Solid waste management; UESP: Urban Environmental Sanitation Program 


\section{Acknowledgements}

Thanks are due to staff of Kumasi Metropolitan Assembly and the anonymous reviewers and the editors of the journal for their great and constructive comments.

\section{Funding}

This research did not benefit from any source of funding and was carried out with researcher's own resources.

\section{Availability of data and materials}

The data that was generated during the study are not publicly available. The reason being that the data were mainly obtained from the field through in-depth interviews. However, the data are available from the corresponding author on reasonable request.

\section{Author's contributions}

The author conceived the idea and did the preliminary write-up. He performed the analyses; drafted and edited the manuscript. The author read and approved the final manuscript.

\section{Competing interests}

The author declares that he has no competing interests.

\section{Publisher's Note}

Springer Nature remains neutral with regard to jurisdictional claims in published maps and institutional affiliations.

Received: 14 February 2019 Accepted: 6 August 2019

Published online: 26 August 2019

\section{References}

Baud, I. S. A. (2001). Local Governance and Partnership: Implications for an Urban Habitat. Paper presented at CERES Summer School, University of Wageningen, 4th July 2001

Chen, M. A. (2012). The informal economy: Definitions, theories and policies; WIEGO working paper no 1.

Cointreau, S. (2006). Occupational and environmental health issues of solid waste management special emphasis on middleand lower-income countries. Washington, DC: The World Bank, pp. 1-57.

Davis, M. (2006). Planet of Slums. London, UK: Verso.

Dunn, K. (2010). Doing qualitative research in human geography. In I. Hay (Ed.), Qualitative research methods in human geography (pp. 99-137). Docklands: Oxford University Press ANZ.

Forbes, D., L., McLean, R., F., Tsyban, A., Burkett, V., Codignott, J., O., Mimura, N., Ittekkot, V. (2001). Coastal Zones and Marine Ecosystems. 264 Geography Reader. In: James J, Canziani MOF, Leary NA, Dokken DJ, White KS (eds) Climate Change 2001: Impacts, Adaptation, and Vulnerability. Cambridge University Press, UK, pp 343-379.

Gërxhani, K. (2004). The informal sector in developed and less developed countries: A literature survey. Public Choice, $120,267-300$

Gough, K. V., \& Langevang, T. (2016). Young entrepreneurs in Sub-Saharan Africa. (spaces of childhood and youth series). Abingdon: Routledge.

Grant, R., \& Oteng-Ababio, M. (2016). The global transformation of materials and the emergence of informal 'Urban Mining' in Accra, Ghana. Africa Today, 62(4), 3-20.

Grosso, M. (2016). Sound and advanced municipal waste management: Moving from slogans and politics to practice and technique. Waste Management \& Research, 34(10), 977-979.

GSS (Ghana Statistical Service). (2008). Ghana living standards survey: Report of the Sixfth round. Accra: Ghana Statistical Service.

Guha-Khasnobis, B., Kanbur, R., \& Ostrom, E. (2006). Beyond formality and informality. In Guha-Khasnobis, Kanbur, \& Ostrom (Eds.), Linking the formal and informal economy: Concepts and policies (pp. 1-18). Oxford: Oxford University Press.

Hart, K. (1973). Informal income opportunities and urban employment in Ghana. Journal of Modern African Studies, 11(1), 61-89.

ILO. (2002). Women and men in the informal economy: A statistical picture. In Employment sector. Geneva: International Labour Office.

Manton, J. (2013). 'Environmental Akalism' and the war on filth. The Personification of Sanitation in Urban Nigeria, Africa, 83(4), 606-622.

Meagher, K. (2003). A back door to globalization? Structural adjustment, globalization and transborder trade in West Africa. Review of African Political Economy, 30(95), 57-75.

Medina, M. (2008). Supporting community-based recycling initiatives in Latin America and the Caribbean. Grassroots Development, 29, 26-31.

Moore, S. A. (2011). Global garbage: Waste, trash trading, and local garbage politics. In: Peet R, Robbins P, and Watts M (eds) Global Political Ecology. Abingdon: Routledge, 133-144.

Obirih-Opareh, N. (2003). Trial and error in privatisation: experiences in urban solid waste collection in Accra and Hyderabad. Urban Studies 40: 837-854.

Onyanta, A. (2016). Cities, municipal solid waste management, and climate change: Perspectives from the South. Geography Compass, 10(12):499-513.

Oteng-Ababio, M. (2010). Private sector involvement in solid waste management in Ghana: The case of the Greater Accra Metropolitan Area (GAMA). Waste Management and Research, 28, 322-329.

Oteng-Ababio, M. (2011). The role of the informal sector in solid waste management in the Gama, Ghana: Challenges and opportunities. Tijdschrift voor Economische en Sociale Geografie, 103(4), 412-425.

Oteng-Ababio, M. (2018). Crossing conceptual boundaries: Re-envisioning coordination and collaboration among women for sustainable livelihoods in Ghana. Local Environment, 23(18), 1-19. 
Oteng-Ababio, M., Arguello, J. E. M., \& Gabbay, O. (2013). Solid waste management in African cities: Sorting the facts from the fads in Accra, Ghana. Habitat International, 39(C), 96-104.

Oteng-Ababio, M., Owusu-Sekyere, E., \& Amoah Samuel, T. (2017). Landfill externalities and property values dilemma-Emerging insights from three Ghanaian cities. Journal of Contemporary African Studies, 35(3), 349-369.

Owusu, G. (2013). Coping with urban sprawl: A critical discussion of the urban containment strategy in a developing country city, Accra. Planum-The Journal of Urbanism, 26(1), 1-17.

Schneider, F. (2005). Shadow economics around the world. What do we really know? European Journal of Political Economy, 21(3), 147-158.

Sustainable Development Solutions Network (SDSN). (2015). Key elements of a successful Addis Ababa accord on financing for sustainable development. Paris and New York: Sustainable Development Solutions Network http://unsdsn.org/wp-content/ uploads/2015/03/20150331-key-elements-for-addisababa-accord.pdf.

Thieme, T. (2017). The hustle economy: Informality, uncertainty and the geographies of getting by. Progress in Human Geography, 42(4):1-20.

Tukahirwa, T. J., Mol, A. P. J., \& Oosterveer, P. (2011). Access of urban poor to NGO/ CBO-supplied sanitation and solid waste services in Uganda: The role of social proximity. Habitat International, 35, 582-591.

UN (2008). The Millennium Development Goals Report 2008. New York, Geneva: UN.

UN (2014). The road to dignity by 2030: ending poverty, transforming all lives and protecting the planet. In Synthesis report of the Secretary-General on the Post-2015 Agenda, December 2014, Para 48.

UNDP (2006). Human Development Report 2006. New York: UN.

Williams, C. C., \& Nadin, S. (2010). The commonality and character of off-the-books entrepreneurship: A comparison of deprived and affluent urban neighbourhoods. Journal of Developmental Entrepreneurship, 15, 1-14.

Wilson, D. C., Rodic, L., Cowing, M. J., Whiteman, A., Stretz, J., Scheinberg, A.(2013) Benchmark Indicators for integrated \& sustainable waste management. ISWA World Congress 2013 - Vienna - 7-9 October 2013.

Yeboah, I. E. A. (1998). What's informal about the informal sector? Culture and the construction of development in sub-Saharan Africa. The East African Geographical Review, 20(1)1-10.

\section{Submit your manuscript to a SpringerOpen ${ }^{\circ}$ journal and benefit from:}

- Convenient online submission

- Rigorous peer review

- Open access: articles freely available online

- High visibility within the field

- Retaining the copyright to your article

Submit your next manuscript at $\boldsymbol{\nabla}$ springeropen.com 